\title{
First Record of Monstrilloid Copepods in Korea: Description of a New Species of the Genus Cymbasoma (Monstrilloida, Monstrillidae)
}

\author{
Cheon Young Chang* \\ Department of Biological Science, Daegu University, Gyeongsan 712-714, Korea
}

\begin{abstract}
A new monstrilloid species belonging to the genus Cymbasoma is described as a preliminary result from nocturnal surveys using a light trap on the east and south coasts of South Korea. Monstrilloid copepods are first recorded in South Korea. Cymbasoma striifrons n. sp. resembles C. striatum (Isaac, 1974) and C. tumorifrons Isaac, 1975 in sharing the character combination of transverse striations on forehead, somewhat small body (generally slightly less or longer than $1 \mathrm{~mm}$ ), single lobed leg 5 bearing a short medial seta in female, and smooth lateral margin of anal somite without notch and wrinkles. However, C. striifrons $\mathrm{n}$. sp. differs from C. striatum by relatively short and swollen cephalothorax, and rather strongly wrinkled genital somite. Cymbasoma striifrons $\mathrm{n}$. $\mathrm{sp}$. is also distinguished from C. tumorifrons in lacking a rounded protuberance on anterior margin of ventral surface and by relatively short cephalothorax and the number of ventral nipple-like processes on cephalothorax. Herein the new species is described and illustrated, with some comments on the morphological comparison with its allied species.
\end{abstract}

Keywords: Copepoda, Cymbasoma striifrons, East Asia, light trap, new species, taxonomy

\section{INTRODUCTION}

Monstrilloids are basically endoparasitic copepods, before free-living, non-feeding adult stage (Boxshall and Halsey, 2004). Polychaetes and prosobranch mollusks have been known as their hosts. Recently, monstrilloids were also found in sponges (Huys et al., 2007), and were reported to be highly prevalent within the mantle of brown mussels (Suárez-Morales et al., 2010). Although the generic nomenclature is still unsettled, 116 species of four genera are currently recognized in the single family Monstrillidae Dana, 1849 (Razouls et al., 2005-2012; Suárez-Morales, 2011). Among the four genera, the major ones are Monstrilla Dana, 1849 and Cymbasoma Thompson, 1888, latter of which comprises 41 species, about one-third of all recorded monstrilloid species.

In Korea, taxonomic study on monstrilloid copepods is still entirely lacking. As a preliminary result from nocturnal surveys using a light trap on the east and south coasts of South Korea, we describe a new monstrilloid species belonging to the genus Cymbasoma, C. striifrons n. sp.

\section{MATERIALS AND METHODS}

Materials examined in the present study were collected using a light trap. The light trap is made with a PVC pipe $(10 \mathrm{~cm}$ in diameter, $42 \mathrm{~cm}$ long) and a flashlight for SCUBA divers, placed on rocky or sandy bottom of 3-6 $\mathrm{m}$ in depth at the end of piers or seawalls in small harbors after sunset. The samples caught in the light trap for overnight were filtered through a plankton net with $64 \mu \mathrm{m}$ mesh at dawn. Monstrilloid copepods were fixed in $4 \%$ buffered formalin or $95 \%$ ethanol in the field and later sorted under a stereomicroscope in laboratory. Most specimens were transferred to $80 \%$ ethanol for storage or for being deposited in the institute.

Specimens were dissected and mounted in lactophenol on the Cobb slide, after treatment in a solution of $10 \%$ glycerin$90 \%$ ethyl alcohol for 1-2 days. Dissection was performed using two needles made from a $0.3 \mathrm{~mm}$-diameter tungsten wire, sharpened by electrolysis (Huys and Boxshall, 1991). Mounted specimens were observed using a differential interference contrast microscope (BX-51; Olympus, Tokyo, Japan) (c) This is an Open Access article distributed under the terms of the Creative Commons Attribution Non-Commercial License (http://creativecommons.org/ licenses/by-nc/3.0/) which permits unrestricted non-commercial use, distribution, and reproduction in any medium, provided the original work is properly cited.

pISSN 2234-6953 eISSN 2234-8190
*To whom correspondence should be addressed

Tel: 82-53-850-6454, Fax: 82-53-850-6459

E-mail: cychang@daegu.ac.kr 
equipped with Nomarski optics. All drawings were made with the aid of a camera lucida. Measurements were carried out with a digital camera for microscope (Cool SNAP 5.0M; Roper Scientific Co., Tucson, AZ, USA) and a calibration software QCapture Pro (ver. 5.0, Media Cybernetics Inc., Bethesda, MD, USA).

The type material of the new species is deposited in The National Institute of Biological Resources (NIBR), Korea (nos. NIBRIV0000245160 to NIBRIV0000245161). Additional materials are deposited in the Department of Biological Science, Daegu University (nos. DB20039 to DB20041), Korea.

Terminology for general copepod morphology follows Huys and Boxshall (1991). The antennular armature is described according to the nomenclature proposed by Grygier and Ohtsuka (1995).

\section{SYSTEMATIC ACCOUNTS}

Order Monstrilloida Sars, 1903

Family Monstrillidae Dana, 1849

Genus Cymbasoma Thompson, 1888

Cymbasoma striifrons new species (Figs. 1-3)

Material examined. Holotype: Adult female (NIBRIV0000 245160), undissected, ethanol-preserved; Korea: Gangwondo, Samcheok-si, Gyo-dong, Hujin Harbor, 37 $27^{\prime} 52.79^{\prime \prime} \mathrm{N}$, $129^{\circ} 10^{\prime} 43.41^{\prime \prime}$ E, 26 Jul 2010, Chang CY, Lee DY, Yoo JG.

Paratypes: 2 females (NIBRIV0000245161), undissected, ethanol-preserved, same collection data as in holotype. Additional material: 2 females (DB20039, 20040), dissected on slides, same collection data as in holotype; 1 female (DB20 041), Gyeongsangbuk-do, Geoje-si, Nambu-myeon, Ssanggeun dock, $34^{\circ} 45^{\prime} 50.69^{\prime \prime} \mathrm{N}, 128^{\circ} 35^{\prime} 10.71^{\prime \prime} \mathrm{E}, 6$ Aug 2011, Chang CY, Yoo JG.

Etymology. The specific name striifrons is taken from the Latins stria and frons, each meaning 'furrow, line' and 'forehead, face,' which refers to the band of transverse striations on forehead.

Description. Female: Body (Fig. 1A, B) rather slender and relatively small, 1.1-1.4 mm long (mean $1.28 \mathrm{~mm}$, standard deviation $0.12, n=6$ ), measured from anterior end of cephalothorax to posterior margin of caudal rami, excluding caudal setae. Cephalothorax relatively short, accounting for $48 \%$ of total body length; anterior third swollen laterally. Anterior part of dorsal surface of cephalic region nearly smooth, except for a pair of short sensilla and fine wrinkles near anterior margin of cephalothorax. Nauplius eye well developed, round in dorsal view, about $0.06 \mathrm{~mm}$ in diameter. Ocelli beside nau- plius eye round, fairly apart to each other, separated by distance equal to $75 \%$ of eye diameter, about $120 \%$ the diameter of each ocellus, in dorsal view. Paired ventral nipple-like processes situated between antennular bases and oral papilla (Fig. 3A), just behind eyes; 2 small sensory pores present between the processes. Oral papilla lying somewhat anteriorly, 0.17 of way back along cephalothorax (Figs. 1B, 3A). Weak wrinkles present around oral papilla and nipple-like processes. Anterior part of cephalothorax with a wide band of fine transverse cuticular striations running around the body, covering almost a quarter (23-25\%) of cephalothorax.

Antennules (Figs. 1A, B, 2B) short and relatively stumpy, about $15 \%$ of total body length, and about $31 \%$ as long as cephalothorax; 4-segmented, second and third segments not well defined or partly fused; ratio of lengths of segments 13.3 : 28.9: $14.4: 43.4=100$. Armature: segment 1 with 1 ; segment 2 with $2 \mathrm{~d}_{1-2}, 2 \mathrm{v}_{1-3}$, IId; segment 3 with 3 , IIIv, IIId; segment 4 with $4 \mathrm{v}_{1-3}, \mathrm{IVv}, \mathrm{IVd}, 4 \mathrm{~d}_{1-2}$, 4 aes, Vm, Vd, Vv, 5, 6 ${ }_{1-2}, \mathrm{~b}_{1-6}$, 6 aes; distal 2 chela-like spines $\left(6_{1}\right.$ and $\left.6_{2}\right)$ with different lengths, length ratio 1.4-1.5.

Cephalothorax incorporating first pedigerous somite. Prosome compring cephalothorax and 3 thoracic somites, each bearing pair of biramous swimming legs, with both endopods and exopods 3-segmented. Coxa of legs 1-4 lacking seta; intercoxal sclerite subrectangular, with paired lateral lobes slightly produced distally and smooth distal margin; both anterior and posterior surfaces smooth without transverse spinule or setule row. Coxa and basis not fully devided. Basis lacking seta distomedially; outer proximal seta slender, naked. First and second endopodal segments of legs 1-4 swollen outer posteriorly with hairs along corner. Outer distal spines on first and third exopodal segments of legs 1-4 feeble, not ornamented with secondary spinules; inner distal seta on first exopodal segments of legs 1-4 slender and short, slightly exceeding over distal margin of second exopodal segment; outer distal setae on third exopodal segments of legs 1-4 spiniform, with heterogeneous ornamentation along outer and inner margins. Seta/Spine armature on swimming legs 1-4 as follows (Roman numerals indicate number of spines, and Arabic numerals indicate number of setae):

\begin{tabular}{lcccc}
\hline & Coxa & Basis & Exopod & Endopod \\
\hline Leg 1 & $0-0$ & $1-0$ & I-1; 0-1; I,1,3 & $0-1 ; 0-1 ; 1,2,2$ \\
Legs 2-4 & $0-0$ & $1-0$ & I-0; 0-1; I,1,4 & $0-1 ; 0-1 ; 1,2,2$ \\
\hline
\end{tabular}

Urosome (Fig. 2A) consisting of fifth pedigerous somite, genital double-somite, anal somite, with caudal rami; ratio of lengths $32.3: 40.4: 27.3=100$. Genital double-somite strongly swollen in the anterior half, rather globose, with transverse wrinkles in the middle of dorsal surface and lateral sides of 
Cheon Young Chang
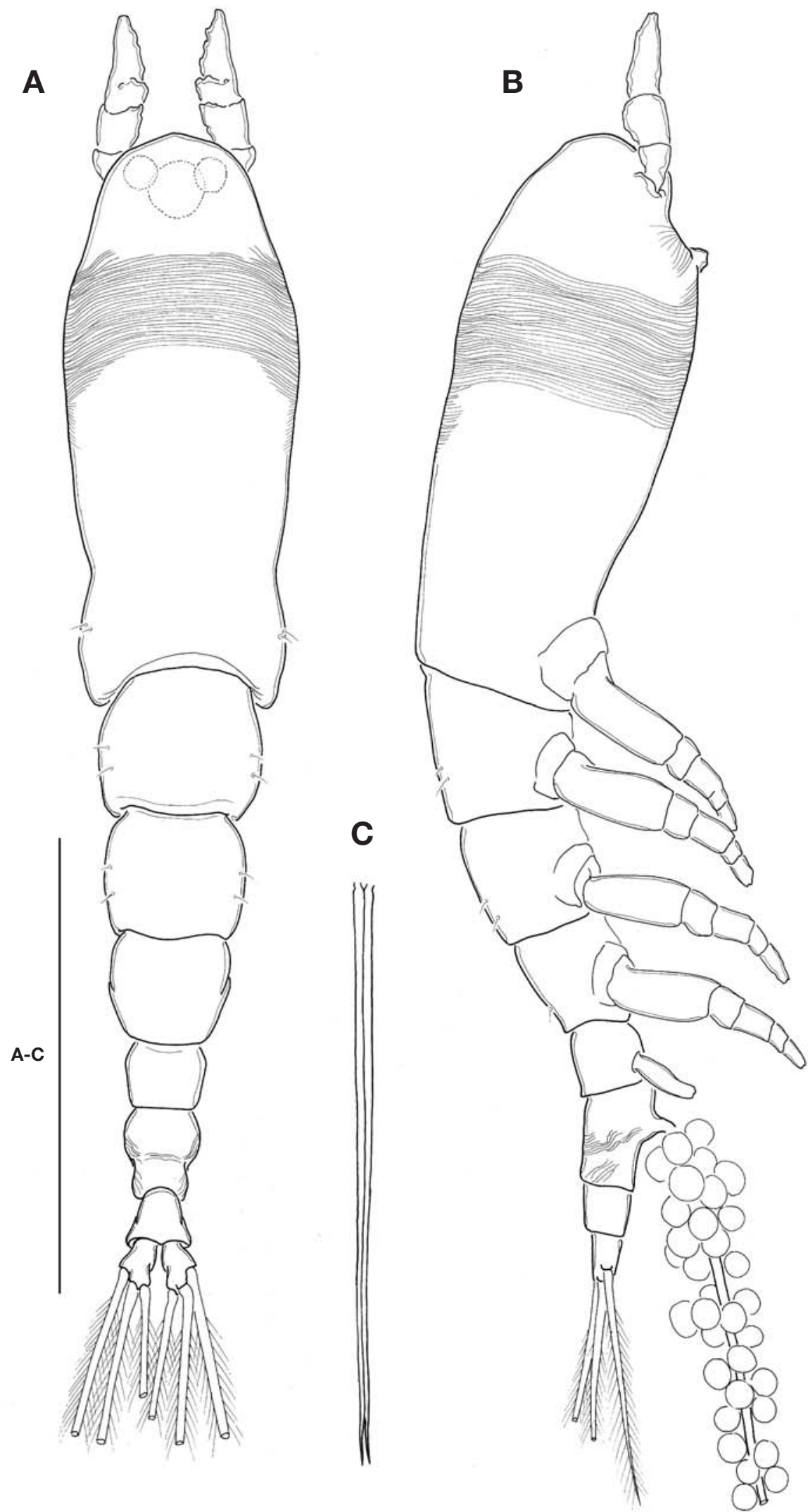

Fig. 1. Cymbasoma striifrons n. sp., female. A, Habitus, dorsal; B, Habitus, lateral; C, Ovigerous spines. Scale bar: A-C=500 $\mu$ m. 


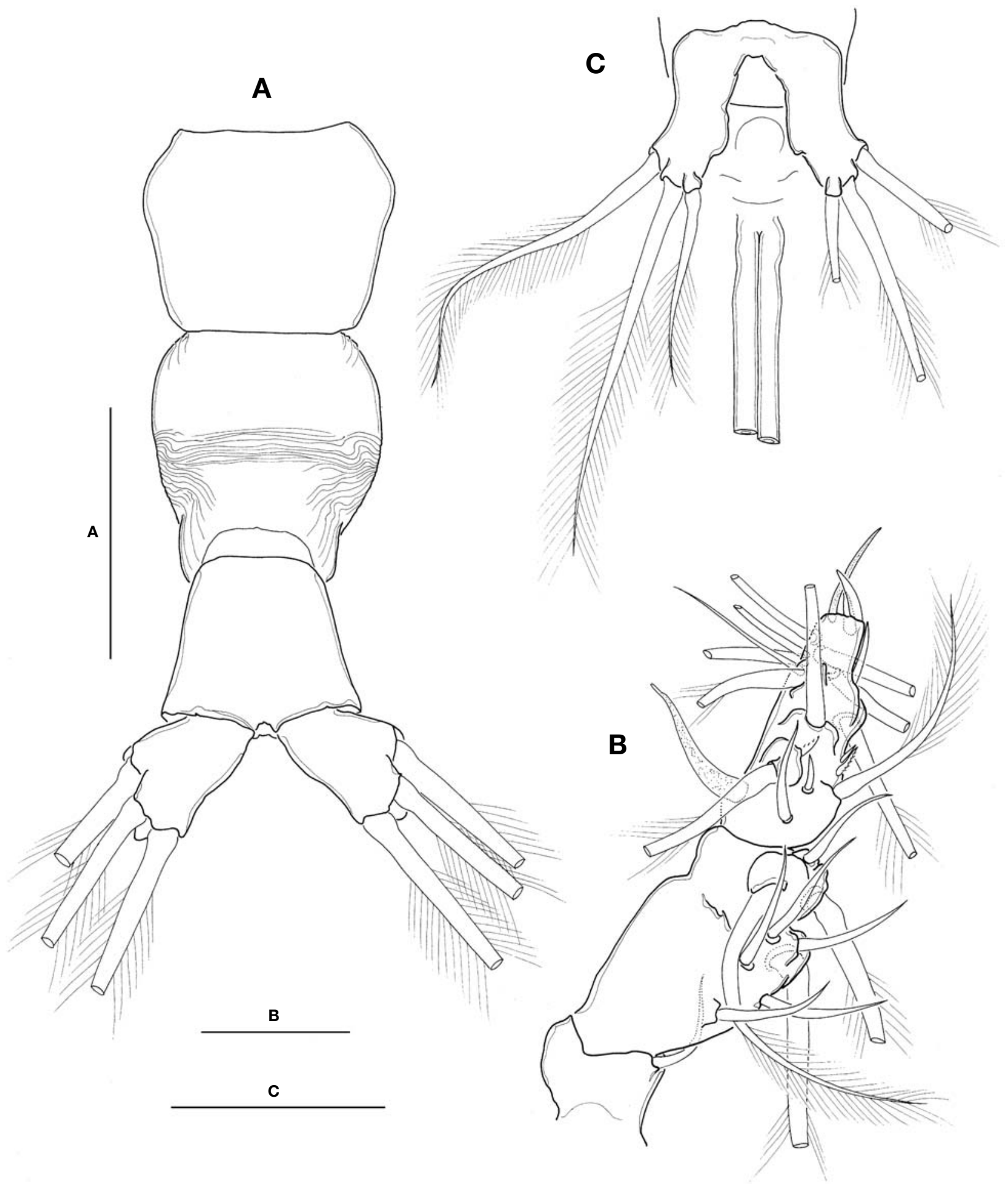

Fig. 2. Cymbasoma striifrons n. sp., female. A, Urosome, dorsal; B, Antennule; C, Leg 5 and basal part of ovigerous spines, ventral. Scale bars: $A, C=100 \mu \mathrm{m}, B=50 \mu \mathrm{m}$.

posterior half; outer distal corner not produced (Fig. 2A). Genital double-somite bearing pair of long ovigerous spines, inserted on middle of ventral surface, basally separated, representing nearly half (49.4\%) of total body length, about 2.7 


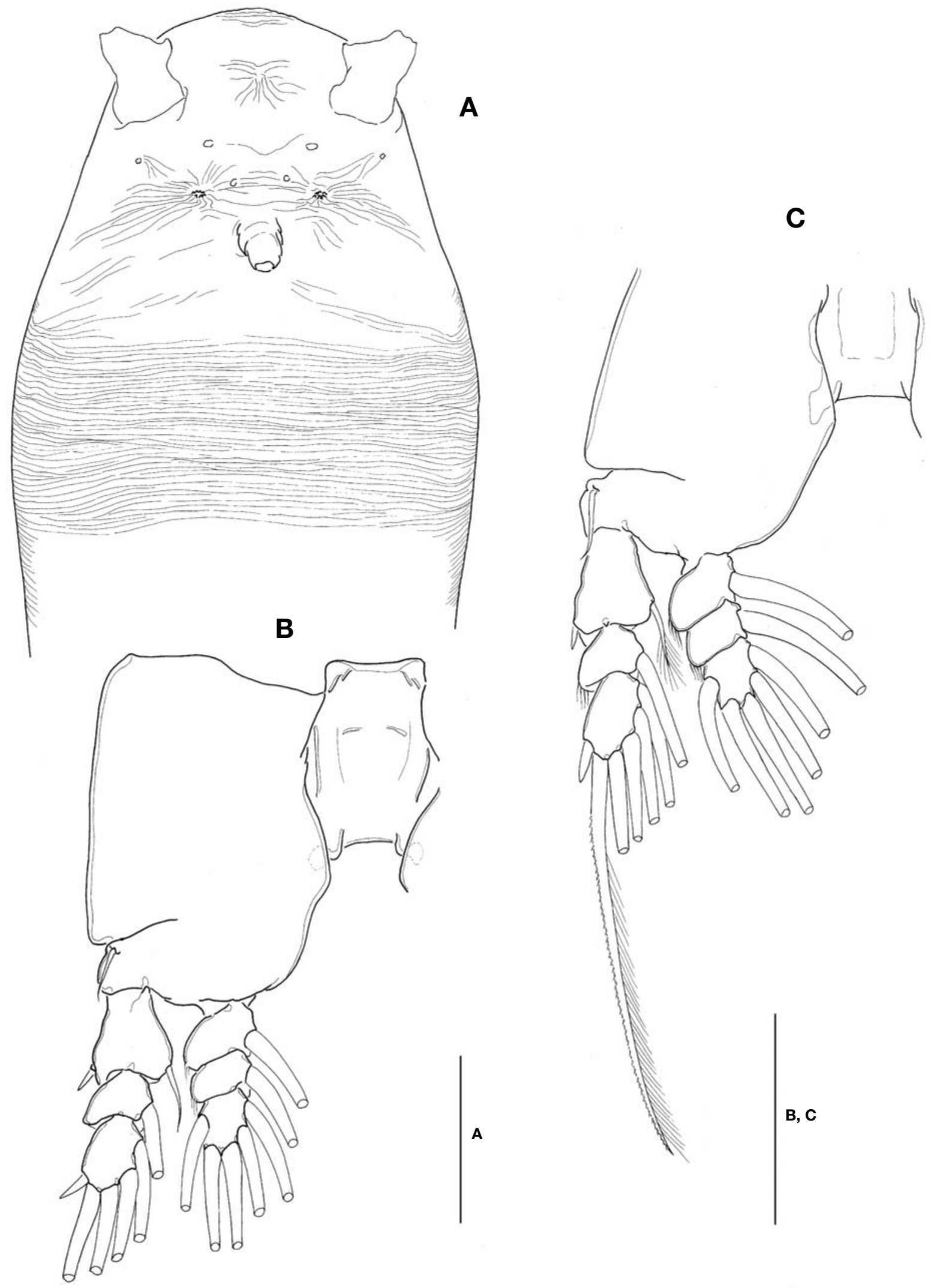

Fig. 3. Cymbasoma striffrons n. sp., female. A, Forehead of cephalothorax, ventral; B, Leg 1; C, Leg 4. Scale bars: A-C=100 $\mu$ m. 
times longer than urosome, with tips pointed, not-swollen (Figs. 1C, 2C), extending slightly beyond tips of caudal setae. Anal somite trapezoid; lacking wrinkles or striae both on dorsal and ventral surfaces; lateral margin nearly smooth, without apparent notch.

Leg 5 (Fig. 2C) single lobed, medial margin slightly swollen, representing vestige of endopodal lobe; armed with 3 plumose setae, comprising 2 outer subequal in length and breadth, and innermost one smallest and about $1 / 2$ times as long as others.

Caudal rami (Fig. 2A) highly divergent; ramus subquadrate, with slightly concave inner margin, 1.5 times longer than wide; furnished with 2 terminal and 1 lateral setae, subequal in length and breadth.

Male: Unknown.

Remarks. This species is assigned to the genus Cymbasoma by virtue of the presence of only one free postgenital somite, that is, anal somite, in female, and bearing 3 caudal setae. Among 40 congeneric species in the checklist of Razouls et al. (2005-2012), this new species is discriminated from the following species group: C. longispinosum (Bourne, 1890), C. reticulatum (Giesbrecht, 1893), C. gigas (Scott, 1909), C. morii (Tokioka, 1949), C. chelemense Suárez-Morales and Escamilla, 1997, C. bowmani Suárez-Morales and Gasca, 1998, and C. californiense Suárez-Morales and PalomaresGarcia, 1999, which share large body (usually much longer than $2 \mathrm{~mm}$ ), remarkably elongate cephalothorax (more than 2/3 of whole body length) and relatively long ovigerous spine (usually longer than whole body) (see Table 1 in Suárez-Morales and Palomares-Garcia, 1999).

Although the genuine identity of Cymbasoma rigidum Thomson, 1888, which is likely to be a species complex with different morphotypes (see Suárez-Morales, 2006), has not been clearly conformed, $C$. striifrons $n$. sp. apparently differs from $C$. rigidum s.l. by a much smaller body (far less than 2 $\mathrm{mm}$ long) and smooth lateral margins of anal somite lacking notch as well as the conspicuous band of transverse striations on the forehead of cephalothorax, as suggested in the specific name.

As far as my knowledge, the distinguishable band of transverse striations around the body on the forehead, the decisive character of $C$. striifrons n. sp., is shared with only one congeneric species, C. striatum (Isaac, 1974) from English Channel, and Monstrillopsis ferrarii Suárez-Morales and Ivanenko, 2004 from the White Sea. Besides that, C. striifrons n. sp. is similar to C. striatum in having the character combination of somewhat small body (generally slightly shorter or longer than $1 \mathrm{~mm}$ ), a single lobed leg 5 bearing a short, slender medial seta in female, smooth lateral margins of anal somite without notch and wrinkles. However, $C$. striifrons n. sp. differs from $C$. striatum by relatively short cephalothorax (about
$48 \%$ of total body length vs. $55 \%$ in C. striatum), which is somewhat swollen in the anterior third in the new species, rather strongly wrinkled genital somite, and much shorter aesthetasc (4aes) on the last segment of antennules (strikingly long, and far exceeding the distal end of the last segment in C. striatum) (see Suárez-Morales, 2000).

Although the band of transverse striation on the forehead is rather faint and very narrow, C. tumorifrons Isaac, 1975 from the Mediterranean (off Toulon, France) and Mexican Pacific is also similar to $C$. striifrons $\mathrm{n}$. $\mathrm{sp}$. in having a single lobed leg 5 and a globose genital double-somite with wrinkles. However, depending on the detailed redescription by Suárez-Morales and Alvarez-Silva (2001), C. tumorifrons clearly differs from $C$. striifrons $n$. sp. by a rounded protuberance on the anterior margin of ventral surface, a relatively longer cephalothorax (55\% in C. tumorifrons vs. $45 \%$ in $C$. striifrons), the number of ventral nipple-like processes on the cephalothorax ( 2 pairs in $C$. tumorifrons vs. 1 pair in $C$. striifrons), and the length ratio between two terminal spines of antennule (subequal in $C$. tumorifrons vs. about 1.5 in $C$. striifrons).

Cymbasoma quintanarooense (Suárez-Morales, 1994) from Mexican coast of the Caribbean Sea has a well-defined transverse striation band only on the dorsal surface of cephalothorax, according to the detailed redescription of Suárez-Morales and Escamilla (2001). This species is similar to C. striifrons n. sp. in having the single lobed leg in female, anteriorly globose genital double-somite with wrinkles and smooth lateral margin of anal somite without suture and wrinkles. However, C. quintanarooense is evidently different from C. striifrons by relatively larger body (around $2 \mathrm{~mm}$ long), relatively elongated cephalothorax (59\% of total body length), dorsolateral patches of longitudinal striations just behind ocelli, and a round protuberance on ventral anterior margin of genital double-somite.

This species is the 18th monstriiloid species recorded from the Far-East Asian waters in the northwest Pacific, and eleventh species described as new to science in the area (cf. Razouls et al., 2005-2012; Suárez-Morales, 2011).

\section{ACKNOWLEDGMENTS}

I am grateful to Dr. Jimin Lee (Daegu University, Korea) for her illustrations. I thank Dr. Mark Grygier all for the words of encouragement to initiate the monstrilloid taxonomy. I am indebted to Dr. Chad Walter (Smithsonian Institution, USA) for providing lots of references. I also appreciate two anonymous reviewers for their critical comments that greatly improved the manuscript. This research was supported by Basic Science Research Program through the National Research 
Foundation of Korea (NRF) funded by the Ministry of Education, Science and Technology (2011-0009839), and by the project of "Discovery of indigenous species from Korea" sponsored by the National Institute of Biological Resources (NIBR) under the Ministry of Environment, Korea.

\section{REFERENCES}

Boxshall GO, Halsey SH, 2004. An introduction to copepod diversity, vol. I. The Ray Society, London, pp. 1-421.

Grygier MJ, Ohtsuka S, 1995. SEM observation of the nauplius of Monstrilla hamatapex, new species, from Japan and an example of upgraded descriptive standards for monstrilloid copepods. Journal of Crustacean Biology, 15:703-719.

Huys R, Boxshall GA, 1991. Copepod evolution. The Ray Society, London, pp. 1-468.

Huys R, Llewellyn-Hughes J, Conroy-Dalton S, Olson PD, Spinks JN, Johnston DA, 2007. Extraordinary host switching in siphonostomatoid copepods and the demise of the Monstrilloida: integrating molecular data, ontogeny and antennulary morphology. Molecular Phylogenetics and Evolution, 43:368-378.

Razouls C, de Bovée F, Kouwenberg J, Desreumaux N, 20052012. Diversity and geographic distribution of marine planktonic copepods [Internet]. Centre National de la Recherche Scientifique and Université Pierre et Marie CURIE, Paris, Accessed 26 Feb 2012, <http://copepodes.obs-banyuls.fr/en /index. php>.

Suárez-Morales E, 2000. Redescription of two species of Cym- basoma from southwest Britain and from Indonesia (Copepoda: Monstrilloida), with notes on taxonomy. Beaufortia, 50:139-149.

Suárez-Morales E, 2006. Validation and redescription of Cymbasoma germanicum (Timm) (Crustacea: Copepoda: Monstrilloida) from Helgoland with comments on Cymbasoma rigidum Thompson. Helgoland Marine Research, 60:171-179.

Suárez-Morales E, 2011. Diversity of the Monstrilloida (Crustacea: Copepoda). PLoS ONE, 6:e22915.

Suárez-Morales E, Alvarez-Silva C, 2001. Cymbasoma tumorifrons (Copepoda: Monstrilloida): an expanded description based on a new collection from the eastern tropical Pacific. Pacific Science, 55:183-189.

Suárez-Morales E, Escamilla JB, 2001. Taxonomic report on some monstrilloids (Copepoda, Monstrilloida) from southeast Mexico with the description of a new species of Monstrilla. Journal of Natural History, 35:1433-1445.

Suaráz-Morales E, Palomares-García R, 1999. Cymbasoma californiense, a new monstrilloid (Crustacea: Copepoda: Monstrilloida) from Baja, California, Mexico. Proceedings of the Biological Society of Washington, 112:189-198.

Suárez-Morales E, Scardua MP, da Silva PM, 2010. Occurrence and histopathological effects of Monstrilla sp. (Copepoda: Monstrilloida) and other parasites in the brown mussel Perna perna from Brazil. Journal of the Marine Biological Association of the United Kingdom, 90:953-958.

Received March 13, 2012

Revised April 3, 2012

Accepted April 6, 2012 